\title{
Formation of transparent and ohmic nanostructure thin films of fluorine- doped indium oxide prepared by spray
}

\author{
S.M. Rozati*, Z. Bargbidi \\ Department of Physics, University of Guilan, Rasht 42335, Iran \\ * Corresponding author. Tel: +981313220912, Fax: +981313220066, E-mail: smrozati@guilan.ac. ir
}

\begin{abstract}
In this research, indium oxide nanostructure undoped and doped with $\mathrm{F}$ were prepared on glass substrates using spray pyrolysis technique. Various parameters such as dopant concentration, deposition temperatures, amount of indium oxide powder were discussed. Structural properties of these films were investigated by XRD \& SEM. Electrical and optical properties have been studied by Hall Effect and UV-Visible spectrophotometer respectively. The thickness of the films is determined by PUMA software. The variation in refractive index, extension coefficient and band gap of these films also were investigated.
\end{abstract}

Keywords: Indium oxide,Indium doped oxide,Spray pyrolysis

\section{Introduction}

Transparent conducting oxide (TCO) such as $\mathrm{In}_{2} \mathrm{O}_{3}, \mathrm{ZnO}, \mathrm{SnO}_{2}$ and $\mathrm{In}_{2} \mathrm{O}_{3}: \mathrm{Sn}$ (ITO) and $\mathrm{In}_{2} \mathrm{O}_{3}: \mathrm{F}$ (IFO) because of their high optical transparency in the visible region, good electrical conductivity are important. These characteristics are required in various applications research fields dealing with transparent heating elements for air craft and car windows [1], photovoltaic devices [2], solar cell [3], gas sensors [4]. A variety of deposition techniques such as vacuum evaporation [5], sputtering [6], spray pyrolysis [7], sol-gel [8], etc. have been used. All of these methods have advantages and disadvantage, but spray pyrolysis has a noticeable advantage, it is a low-cost and non-vacuum technique for large area applications. $\mathrm{In}_{2} \mathrm{O}_{3}$ transparent conducting thin films are n-type semiconductors with wide energy band gap equal to $3.6 \mathrm{eV}$. The structure of $\mathrm{In}_{2} \mathrm{O}_{3}$ in its crystalline form is body centred cubic with lattice constant $\mathrm{a}=10.118 \AA$.Doping indium oxide with fluorine, zinc, tin etc. as donor impurities yields films with low sheet resistance [1].This paper describes the results of our study in an attempt to correlate the electrical conduction with the optical and structural properties of prepared $\operatorname{In}_{2} \mathrm{O}_{3}: \mathrm{F}$ thin films.

\section{Experimental Details}

The chemical spray pyrolysis technique is one of the most commonly used techniques for preparation of transparent and conducting oxides owning to its simplicity, non-vacuum system of deposition and hence inexpensive method. The spray pyrolysis apparatus used in this work consists of a home made spraying unit, substrate holder with heater, and enclosure. The glass substrate is kept on a stainless steel (ss) plate. The heater is capable of heating the substrate up to a temperature of $700^{\circ} \mathrm{C}$. The carrier gas used in all the experiments was air, which is supplied from an air compressor. The air produced by the compressor was first filtered and then connected to the glass spray-gun (atomizer) through a flow meter for controlling its flow. The custom glass spray gun having a nozzle diameter of $0.2 \mathrm{~mm}$ was positioned at a distance of $30 \mathrm{~cm}$ above the substrate. The whole assembly is kept in an enclosure connected to an exhaust.

In this research, $\operatorname{In}_{2} \mathrm{O}_{3}: \mathrm{F}$ thin films were prepared by spraying a water solution containing indium chloride $\left(0.2 \mathrm{gr} \mathrm{InCl}_{3}\right)$ and $\mathrm{NH}_{4} \mathrm{~F}$ used as dopant onto glass substrates heated at 
different substrate temperatures. The structural, electrical, and optical properties of TCOs are strongly affected by the temperature of substrate.

Deposition of parameters conclude: distance between the spray nozzle an substrates $25 \mathrm{~cm}$, the carrier gas using filtered compressed air, the spray rate $191 \mathrm{it} / \mathrm{min}$, volume of solution is 40 $\mathrm{ml}$. All the above mentioned parameters were kept constant and only the concentration of $\mathrm{NH}_{4} \mathrm{~F}(0-15 \mathrm{wt} \%)$ and substrate temperature $\left(400-600{ }^{\circ} \mathrm{C}\right)$ were changed.

In this work we first optimize the concentration of $\mathrm{F} w \mathrm{wt} \%$ using electrical resistivity and optical transparency and secondly focused on the effect of substrate temperature on structural, electrical, optical properties of the samples with a constant fluorine concentration of $2 \mathrm{wt} \%$.

X-ray diffraction (XRD) (Philips-pw-1830) was used to characterize the crystal structure of the films. Morphology of the films was examined by Cambridge scanning electron microscopy (SEM). The optical measurements of the $\operatorname{In}_{2} \mathrm{O}_{3}: \mathrm{F}$ thin films were carried out at room temperature using UV-Visible spectrophotometer( Cary 100 Scan Version).The electrical properties of thin films measured by Hall effect and Vander-Pauw set-up(RH 2010 PhysTech system).

\section{Results and Discussion}

Concentration of $\mathrm{F}$ in these films have been varied from $0-15 \mathrm{wt} \%$. As a result, the resistivity decreased quickly with increasing F concentration reaching a minimum of $\rho=1.35 \times 10^{-3} \Omega \mathrm{cm}$ for an $\mathrm{F}$ concentration of $1 \mathrm{wt} \%$ which demonstrate a good ohmic contact for electrode applications. For higher dopant content, the resistivity increased (Table 1). The higher transmittance observed in the films for $2 \mathrm{wt} \%$ of $\mathrm{F}$ doped. Since we were looking for a layer with both high transparent and good resistevity, we used figure of merit (FOM). Thus the optimized layer with $2 \mathrm{wt} \%$ of $\mathrm{F}$ concentration was selected according to the most FOM [9].

The X-ray diffraction result of IFO films in various concentrations are shown that, films are polycrystalline and crystallize in a cubic structure with preferential orientation along (222) and (400). Note also that no characteristic peaks of impurity and dopant phases have been observed.

Substrate temperature is an important parameter for spray pyrolysis deposition. It is observed that at lower substrate temperature (less than $250{ }^{\circ} \mathrm{C}$ ), the growth rate is controlled by activated processes. At higher substrate temperature (greater than $550{ }^{\circ} \mathrm{C}$ ), the size of the droplet decreases appreciably due to the evaporation of water molecule, resulting In a homogeneous reaction, the reaction may be completed above the substrate, leading to powder formation. Hence very low and very high temperatures are not suitable for preparation of these TCOs. For investigation of temperature effect on the growth mode, we fixed the doping concentration at $2 \mathrm{wt} \% \mathrm{~F}$ and studied the effect of the substrate temperature on $\mathrm{t}$ he transparency. Figure shows the variation of substrate temperature of IFO films with change in transmission. Films deposited at substrate temperatures of 400 to $450{ }^{\circ} \mathrm{C}$ exhibited less transmission in visible region, while by increasing the substrate temperature we get better transparency (Fig. 1). 
Table 1. The variation of electrical properties of IFO films as a function of dopant concentration deposited at $575{ }^{\circ} \mathrm{C}$.

\begin{tabular}{|c|c|c|c|c|c|c|}
\hline F wt \% & $\mathbf{R}_{\mathrm{sh}}(\mathbf{\Omega} / \square)$ & $\rho\left(\times 10^{-3} \Omega \mathrm{cm}\right)$ & $\mathrm{n}\left(\times 10^{20} \mathrm{~cm}^{-3}\right)$ & $\mu\left(\mathrm{cm}^{2} / \mathrm{V} . \mathbf{s}\right)$ & $\begin{array}{c}\mathbf{T} \% \\
\lambda=550 \mathrm{~nm}\end{array}$ & $\begin{array}{r}\text { FOM } \\
\left(\times 10^{-5}\right)\end{array}$ \\
\hline 0 & 5850 & 147 & 0.06 & 6.71 & 77 & 1.25 \\
\hline 0.5 & 335 & 6.36 & 0.26 & 37.4 & 77 & 21.9 \\
\hline 1 & 96.5 & 1.35 & 2.53 & 18.2 & 68.2 & 22.6 \\
\hline 2 & 140 & 1.92 & 1.13 & 28.6 & 87.6 & 190 \\
\hline 10 & 333 & 8.73 & 0.99 & 7.23 & 77 & 7.79 \\
\hline 15 & 527 & 15.30 & 0.72 & 5.63 & 81 & 23.07 \\
\hline
\end{tabular}

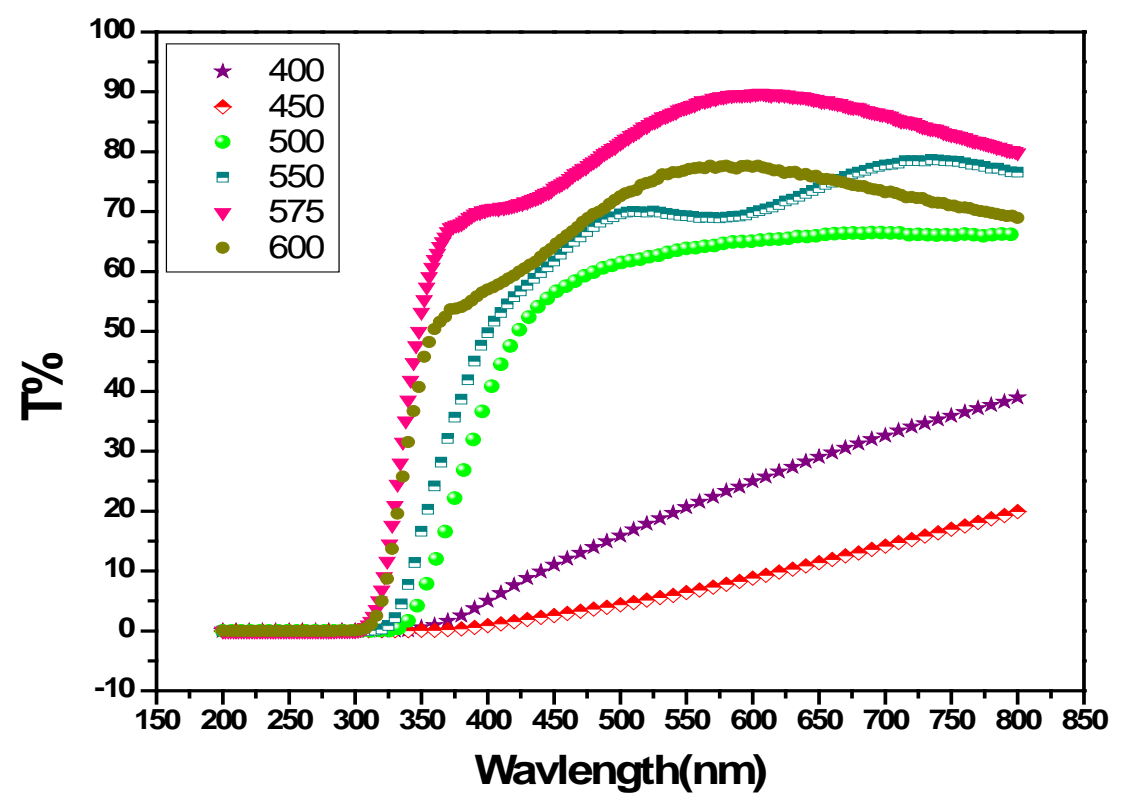

Fig. 1:Optical transmission of IFO films prepared at $2 w t \% \mathrm{~F}$ various substrate temperature

The XRD results (Fig.2) show that, films deposited at substrate temperature of 400 and $450{ }^{\circ} \mathrm{C}$, in addition to (222), (400) peaks have (211), (411), (341), (440), (622) peaks with high intensity. The presence and intensity of peaks decreased with increasing substrate temperature; as a result crystallinity improves leading to well-transmission and resistivity. 

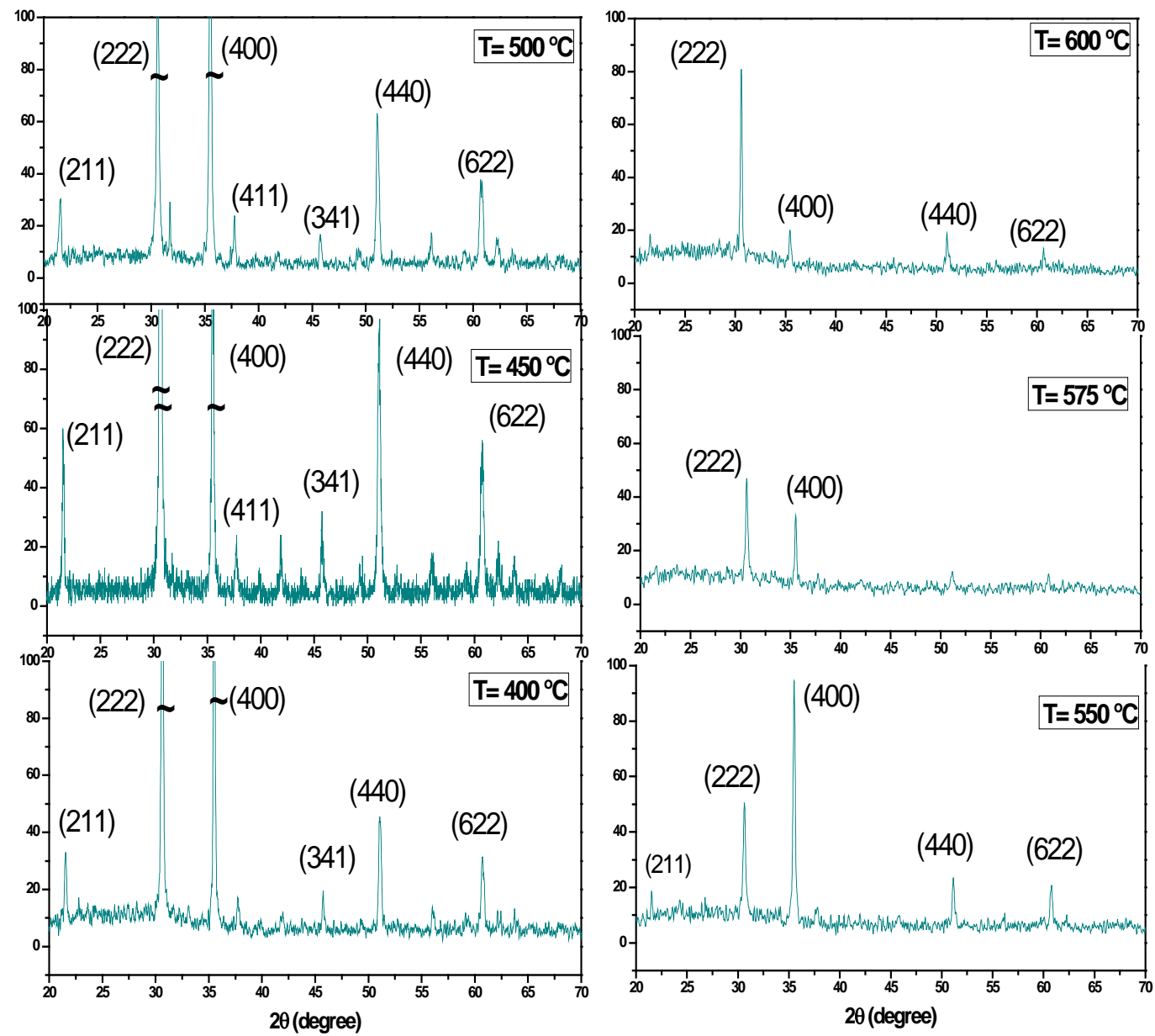

Fig. 2: XRD patterns of IFO films prepared at various substrate temperatures

The SEM results show that the size of crystals is in the range on na nometer. The size of particles changing with respect to deposition parameters. Fig. 3 shows that, the crystalline improved with increasing substrate temperature. Furthermore, the density of grain boundaries and dislocation therefore decreases, leading to the improvement of conductivity and transparency of IFO films.
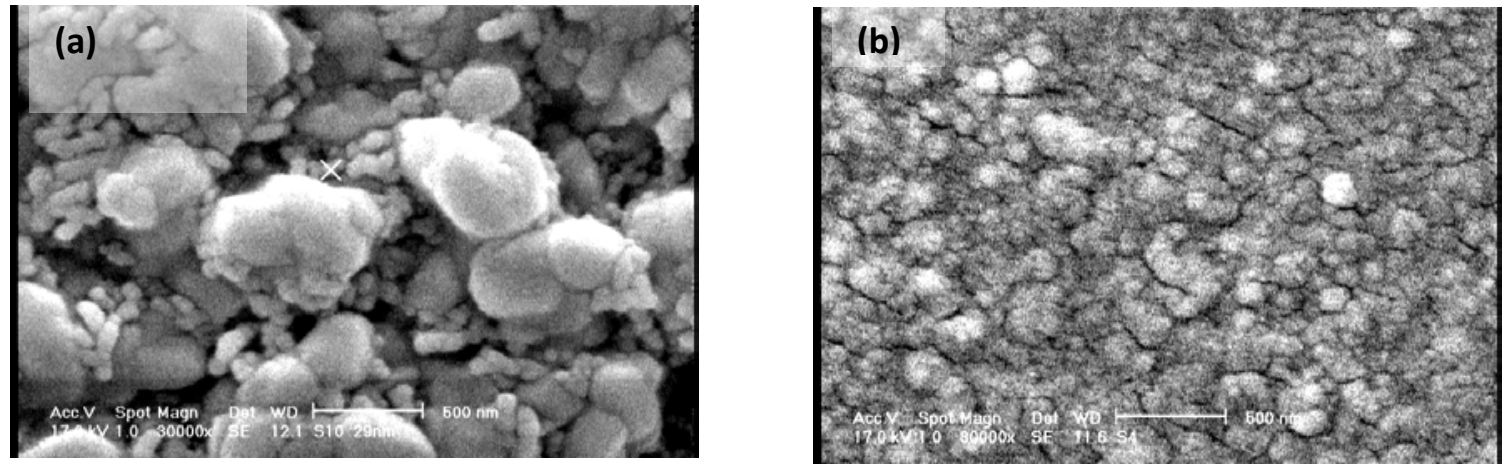

Fig.3 SEM images of IFO films prepared at different substrate temperature: a) $450^{\circ} \mathrm{C}$ and b) $575{ }^{\circ} \mathrm{C}$. 
Subsequently the amount of indium powder also was investigated for the prepared films. Result show that the resistivity is decreased by increasing of indium powder but transparency is decreased. Besides, the thickness of the films is determined by PUMA software [10].

\section{Conclusions}

In this research, fluorine doped indium oxide (IFO) nanostructure were prepared at different $\mathrm{F}$ concentration, substrate temperature and $\mathrm{InCl}_{3}$ concentration using spray pyrolysis technique. Then effects of above parameters on structural, electrical and optical properties of nanostructure thin films of IFO were investigated. The SEM results show that the size of crystals is in the range on nanometer. The size of particles changing with respect to deposition parameters. The presence and intensity of XRD peaks decreased with increasing substrate temperature; as a result crystallinity improves leading to well-transmission and resistivity.In conclusion, the optimum IFO films were prepared using $0.2 \mathrm{gr} \mathrm{InCl}_{3}$ with $\mathrm{F}$ concentration of $2 \mathrm{wt} \%$ at substrate temperature of $575^{\circ} \mathrm{C}$. With this condition sheet resistance was $140 \Omega / \square$ and the optical transmission in visible region was $87.6 \%$.

\section{Acknowledgment}

This work was supported by the department of research of the University of Guilan.

\section{References}

[1] K.I. Chopra, S. Major, D.K. Pandya, Thin Solid Films, 102, (1983), 1.

[2] C.V.R. Vasant Kumar, A.A. Mansingh, J. Appl. Phys., 65, (1989), 1270.

[3] J.A. Anna Selvan, A.E. Delahoy, S. Guo, Y. Li, A new light trapping TCO for nc-Si:H solar cells, Solar Energy Mater. Solar Cells, 90, (2006), 3371-3376.

[4] G. Korotcenkov, V. Brinzari, A. Cerneavschi, Sensors and Actuators B, 98, (2004), 122 129.

[5] S.M. Rozati, S. Mirzapour, M.G. Takwale,B.R. M arathe, V.G. Bhide, Materials Chemistry and Physics, 34, (1993), 119.

[6] S. Boycheva, A.K. Sytchkova, M.L. Grilli, A. Piegari, Thin Solid Films, 515, (2007), 8469.

[7] S. Golshahi, S.M. Rozati, R. Martins, E. Fortunato, Thin Solid Films, 518, (2009), 11491152.

[8] R.B.H. Tahar, T. Ban, Y. Ohya, Y. Takahashi, J. Appl. Phys., 82, (1997), 865.

[9] G. Haacke, J. Appl. Phys., 47 (1976) 4086.

[10]E.J. Biring, I. Chambouleyron, J.M. Martinez, Estimation of the optical constants and the thickness of thin films using unconstrained optimization, Journal of Computational Physics, 155 (1999) 862-880. 